\title{
Artigos
}

Viviane Maria Alessi ${ }^{1}$

Marynelma Camargo Garanhani ${ }^{2}$

\section{As garatujas teatrais nos gestos dos bebês: um estudo bakhtiniano}

Resumo: O presente artigo apresenta algumas ideias bakhtinianas sobre a constituição da linguagem, com destaque para o gesto, atrelado às experiências comunicativas que os bebês podem experimentar nos espaços educativos, com ênfase para os jogos teatrais. São apresentados dois episódios nos quais os bebês expressam, através dos gestos, algumas das inúmeras possibilidades da linguagem teatral presente no contexto infantil, seja através das descobertas realizadas a partir da movimentação do próprio corpo e os efeitos que este produz em contato com a luz, seja através da manipulação de materiais e/ou brinquedos em uma brincadeira de faz de conta. São momentos lúdicos, de brincadeiras e descobertas que permitem o desenvolvimento das garatujas teatrais, ou seja, as primeiras expressões teatrais dos bebês.

Palavras-chave: Gestos. Bebês. Teatro.

\section{The atrical scribblings in babies' gestures: a Bakhtinian study}

Abstract: This article presents some bakthinian ideas about the constitution of language, especially the gesture, coupled with the communicative experiences that babies can experience in educational spaces, with an emphasis on theatrical games. Two episodes are presented in which the babies express, through the gestures, some of the innate possibilities of the theatrical language present in the infantile context, either through the discoveries realized from the movement of the own body and the effects that this produces in contact with the light, either through the manipulation of materials and / or toys in a make-believe play. They are playful moments, of games and discoveries that allow the development of theatrical scrawl, that is, the first theatrical expressions of the babies.

Keywords: Gestures. Babies. Theater.

'Doutora em Educação pela Universidade Federal do Paraná - UFPR. Pedagoga e professora na Secretaria Municipal da Educação de Curitiba. E-mail: vivialessi@hotmail.com

2Doutora em Educação pela Pontifícia Universidade Católica de São Paulo - PUCSP. Professora do Departamento de Educação Física e do Programa de Mestrado e Doutorado em Educação da UFPR. Coordenadora do Grupo de Pesquisa EDUCAMOVIMENTO-NEPIE/UFPR.E-mail: marynelmagaranhani@gmail.com 
Quando nasce um bebê é um corpo humano que vem ao mundo. Passam a existir o corpo e o mundo - o corpo no mundo.

(Boal, 2006, p. 189)

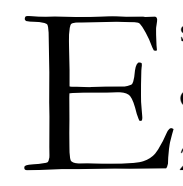

sse mundo, o qual o bebê passa a conhecer, interagir, significar e se constituir, com todo o seu corpo, desde o seu nascimento, é um mundo que "não está dado, mas a fazer" (GERALDI, 2013, p. 7). Este era o lema dos estudos bakhtinianos, que trazema ideia de que, ao nascer, o bebê se insere em um mundo que foi constituído anterior à sua existência, mas que não se encontra pronto e acabado; ao mesmo tempo em que se apropria dos conhecimentos, da linguagem e da cultura construídos pela humanidade, o bebê modifica e ressignifica este mundo.

Todo esse processo ocorre em função da linguagem, uma linguagem múltipla e complexa que os bebês estabelecem desde o nascimento com seus pares e adultos. Enquanto não dominam a linguagem oral, os movimentos expressivos ${ }^{3}$ dos bebês têm um papel primordial no estabelecimento de vínculos e de comunicação com o outro. Conforme afirmam Barbosa e Fochi (2011):

Ao permitirmos experiências para expressar seus sentimentos e suas sensações, por meio do próprio corpo, estamos proporcionando o instrumento ideal para que a criança se comunique com o mundo exterior, o qual vai, aos poucos, tornando-se significativo para ela. Trata-se de uma reflexão acerca das outras linguagens, e não somente sobre a linguagem oral, comumente valorizada e que marginaliza os bebês, uma vez que eles ainda não a dominam. (BARBOSA, FOCHI, 2011, p. 36-37)

Partindo dessa premissa, o presente artigo apresenta algumas ideias debatidas nos estudos bakhtinianos sobre a constituição da linguagem, com destaque para o gesto, atrelado às experiências comunicativas que os bebês podem experimentar nos espaços educativos, com ênfase para os jogos teatrais.

Considerando que "o teatro é uma atividade complexa que trabalha com a construção de signos que se dão por meio das imagens, das palavras, dos sons, dos gestos, dos silêncios" (SILVA, 2015, p. 105), destacamos algumas cenas 4 , obtidas por ocasião das observações realizadas para comporum relatório de tese ${ }^{5}$ sobre a linguagem do bebê e que trazem a dimensão da teatralidade presente no ambiente educacional de/com os bebês.

Assim, na primeira parte apresentamos algumas ideias bakhtinianas centrais sobre a linguagem, perpassando pelo desenvolvimento do gesto e, na segunda parte, trazemos algumas provocações sobre as experiências lúdicas dos bebês com os gestos, os quais mobilizam uma linguagem teatral.

\footnotetext{
3Entendemos por movimento expressivo as atitudes e mímicas que o bebê realiza com o seu corpo na relação com o mundo. ${ }^{4}$ As imagens e observações deste artigo não compõe a versão final da tese publicada, ou seja, foram utilizadas de forma original neste estudo. O estudo, de cunho etnográfico, foi realizado ao longo do período de um ano, por meio da observação de bebês (entre 8 a 24 meses) de uma turma de berçário, em situações cotidianas de interação com seus pares e adultos em um Centro Municipal de Educação Infantil de Curitiba. As observações foram acompanhadas de filmagens e notas de campo. A partir das filmagens foram capturadas as imagens, utilizando o programa Free Studio (free vídeo tojpg converter).

${ }^{5}$ Trata-se da tese intitulada As linguagens dos bebês na Educação Infantil: diálogos do Círculo de Bakhtin com Henri Wallon(ALESSI, 2017).
} 


\section{A construção do gesto: uma perspectiva bakhtiniana}

Os estudos bakhtinianos consideram a linguagem em uma perspectiva dialógica, constituída na interlocução real entre os sujeitos, o que define os sentidos dos enunciados, por meio dos signos constituídos socialmente. Dessa forma, a língua, concreta e viva, deve ser considerada em sua integralidade, de acordo com o contexto no qual foi produzida, em um enfoque translinguístico ${ }^{6}$, que procura entendê-la não pela via formal e estrutural, mas nos sentidos que emergem de seu uso.

A língua não é de modo algum um produto morto, petrificado, da vida social: ela se move continuamente e seu desenvolvimento segue aquele da vida social. Este movimento progressivo da língua se realiza no processo de relação entre homem e homem, uma relação não só produtiva, mas também verbal. Na comunicação verbal, que é um dos aspectos do mais amplo intercâmbio comunicativo - o social -, elaboram-se os mais diversos tipos de enunciações, correspondentes aos diversos tipos de intercâmbio comunicativo social. (VOLÓCHINOV, 2013, p. 157)

Assim, a linguagem, que perpassa e é perpassada pelo sujeito e sua história, é construída e constituída continuamente, em um complexo processo de interação humana, desde a tenra idade. As inúmeras possibilidades de comunicação infantil7, que iniciam muito antes do desenvolvimento da linguagem oral, são construídas permanentemente pela criança, em constante interação com os outros e com o meio no qual está inserida. Para Volochínov os gestos, considerados a primeira e primitiva linguagem da humanidade,

[...] cujos traços se conservam até os nossos dias como auxiliar, usado junto com a linguagem, na gesticulação habitual das mãos e na mímica facial durante a conversação, [...] representa já uma brusca separação do mundo natural, e o começo da criação de um mundo novo, o mundo do homem social, o mundo da história social (VOLÓCHINOV, 2013, p. 142, grifos do autor).

Ao se referir sobre o processo de desenvolvimento humano, o autor complementa essa ideia afirmando que "[...] nos estágios mais elementares do desenvolvimento, a expressão verbal pode ser substituída por outros meios: a linguagem de mãos, gritos inarticulados, mas entonados de modo expressivo etc." (VOLÓCHINOV, 2013, p. 151). Neste sentido, mesmo diante da complexidade da linguagem oral, as outras formas de comunicação utilizadas pelos bebês também têm seu grau de complexidade. Tendo em vista que o bebê precisa se fazer entender para ter suas necessidades e vontades atendidas, e que algumas vezes essa leitura não corresponde à real intenção, temos uma comunicação que consideramos complexa e desafiante: construir uma relação dialógica com os bebês, mesmo quando estes ainda não utilizam a linguagem oral.

Para explicar a origem da linguagem, no ensaio produzido em 1930, Que é a linguagem?, Volóchinov (2013) recorre a estudos de Engels, Ludwig Noiret e Nicolau Marr, que defendem que a linguagem e a vida intelectual surgem em função da atividade/trabalho desenvolvido pelos povos primitivos que precisavam se comunicar uns com os outros.

‘Termo sugerido por "Kristeva no prefácio da edição francesa da poética de Dostoievski" (CASTRO, 2010, p. 94).

${ }^{7}$ Podemos citar os gestos, choro, riso, balbucio, expressões faciais, entre outras. 
Para sobreviver, seja defendendo-se dos animais predadores ou para encontrar coletivamente os alimentos (caçar), os homens primitivos precisavam coordenar as ações para que houvesse uma compreensão mínima dos objetivos em comum. Para esta finalidade criaram a comunicação gestual, baseada em gestos e mímicas.

Essa comunicação não só facilitava a organização do trabalho coletivo, mas também a organização do pensamento social, da consciência social. O psiquismo humano devia cumprir uma tarefa, ainda que elementar, extremamente complexa para aqueles tempos. Em realidade, para a realização da comunicação verbal é necessário que o significado, oculto no gesto da mão do homem, seja compreensivel para o outro homem; que este homem saiba estabelecer - graças à experiência precedente - a relação necessária entre esse movimento e o objeto ou acontecimento em cujo lugar ele é empregado. Em outras palavras, compreender que esse movimento é portador de um significado, que esse movimento expressa um signo. Mas isso não é ainda suficiente. $\mathrm{O}$ signo expresso pelo movimento das mãos não deve ser casual, passageiro. Somente se esse signo se torna constante poderá entrar no horizonte cognoscitivo de um grupo humano, tornarse-á necessário e se converterá num valor social. Como é óbvio, com o crescimento e a transformação da organização econômica, esse signo se modificará gradualmente, mas numa medida quase imperceptível para uma mesma geração de homens que o utilizam. (VOLÓCHINOV, 2013, p. 142-143) (grifos do autor).

Wallon (2008) também analisa a chamada sociedade primitiva ${ }^{8}$ e diferencia gesto prático de gesto ritual. O gesto prático é inventivo, "guiado por uma espécie de intuição plástica que o leva a experimentar e utilizar as qualidades ou propriedades das coisas" (WALLON, 2008, p. 116). Enquanto o gesto ritual é estereotipado, "não significa nada senão relacionado a um protótipo, não tem outro motivo senão obter por intermédio deste um resultado cujas condições e possibilidades não pertencem, pelo menos na sua totalidade, ao campo das circunstâncias presentes" (WALLON, 2008, p. 115).

Contudo, mesmo existindo essa linguagem, também chamada de linguagem das mãos (VOLÓCHINOV, 2013), os gritos de emoção e os rituais mágicos9 envolvendo danças e músicas que permitiam uma certa comunicação social entre os homens, era necessário buscar uma linguagem articulada que atendesse as condições peculiares do trabalho existente nestas sociedades.

O trabalho, ou seja, a organização social necessária ao melhor desempenho das tarefas coletivas desempenhou um papel primordial no nascimento e desenvolvimento da linguagem. Com o tempo e em função do próprio trabalho, surge a necessidade de as pessoas unirem-se em grupos, sejam relacionados aos próprios afazeres ou, de forma mais ampla, com outras tribos. Esses reagrupamentos sociais propiciaram, consequentemente, o entrecruzamento de elementos linguísticos, o que gerou a ampliação e enriquecimento das palavras e, posteriormente, a conjunção de palavras em frases. A linguagem, portanto, "é produto da atividade bumana coletiva e reflete todos os seus elementos tanto na organização econômica como a sociopolitica da sociedade que a gerou" (VOLÓCHINOV, 2013, p. 141) (Grifos do autor).

$\mathrm{O}$ autor reforça, com isso, o caráter social presente na constituição da linguagem, desde as primeiras civilizações. Esta é uma característica fundamental para compreender o processo de construção e desenvolvimento da linguagem na criança pequena, visto que, uma enunciação concreta

\footnotetext{
8 Para isso, Wallon dialoga com estudos da Antropologia.

9 Esses rituais, que envolviam gritos, movimentos das mãos e do corpo, estavam relacionados à crença de sua ação sobre a natureza para a obtenção do alimento (VOLÓCHINOV, 2013).
} 
[...] vive e morre no processo de interação social dos participantes da enunciação. Sua significação e sua forma em geral se definem pela forma e o caráter desta interação. Ao arrancar a enunciação deste chão real que a alimenta, perdemos a chave que abre o acesso de compreensão tanto de sua forma quanto de seu sentido [...] (VOLÓCHINOV, 2013, p. 86).

No livro Marxismo e Filosofia da Linguagem, Volóchinov (2009) reforça essa ideia ao trazer a discussão sobre o signo. $\mathrm{O}$ signo ${ }^{10}$, produzido socialmente pelos indivíduos em um processo de interação social, está imbuído de valores, ele é movimento e intencionalidade. O autor afirma que:

A consciência adquire forma e existência nos signos criados por um grupo organizado no curso de relações sociais. Os signos são o alimento da consciência individual, a matéria de seu desenvolvimento, e ela reflete sua lógica e suas leis. A lógica da consciência é a lógica da comunicação ideológica, da interação semiótica de um grupo social. Se privarmos a consciência de seu conteúdo semiótico e ideológico, não sobra nada. A imagem, a palavra, o gesto significante, etc. constituem seu único abrigo. Fora desse material, há apenas o simples ato fisiológico, não esclarecido pela consciência, desprovido de sentido que os signos lhe conferem. (BAKHTIN/VOLÓCHINOV, 2009, p. 36)

O sentido do signo, portanto, depende do contexto social no qual foi produzido e para compreendê-lo é necessário aproximá-lo de outros signos já conhecidos, ou seja, a “compreensão é uma resposta a um signo por meio de signos" (BAKHTIN/VOLÓCHINOV, 2009, p. 34). Quando a criança aprende a verbalizar uma palavra para indicar uma necessidade, por exemplo, pede mama ao invés de chorar ou apontar, ela está substituindo um signo por outro. Nas palavras de Wallon, “as coisas mudam quando a linguagem não é mais o simples efeito das circunstâncias ou do desejo, quando ela se torna código, ou seja, quando acompanha, não mais as impressões sofridas, mas o ato a ser executado" (WALLON, 2008, p. 183).

\section{Uma luz, um bebê e um brinquedo: garatujas teatrais ${ }^{11}$ no cotidiano}

Desde muito cedo e mesmo sem perceberem, as crianças praticam ações teatrais.

Elas gostam de imitar pessoas do seu convívio próximo e se animam ao vestir roupas e acessórios, realizando atividades de faz de conta. As muito pequenas divertem-se com os adultos por meio de caretas e expressões gestuais. Ao brincar com objetos ou bonecos, tendem a inventar histórias e conversam criando histórias e personagens (CURITIBA, 2011, p. 89).

E no caso dos bebês? Como se dão essas ações lúdicas de caráter dramático? É possível perceber isso na tenra idade?

Primeiramente precisamos trazer à tona, mesmo que de forma breve, algumas considerações acerca da linguagem teatral, superando a visão do bebê como mero espectador. Silva (2015) destaca a

\footnotetext{
10Volóchinov faz a distinção de sinal e signo. Sinal é fixo, preciso e imutável. Signo é vivo, flexível e seu sentido depende do contexto em que ele se insere. A palavra é um sinal apenas no dicionário, enquanto significado estável (BAKHTIN/VOLÓCHINOV, 2009).

11 Termo utilizado por Frabetti (2011) para se referir às precursoras de sinais que incentivam e apoiam a intencionalidade comunicativa. Desde 1985 os atores do grupo La Baracca, Roberto Frabetti e Valeria Frabetti, desenvolvem propostas de teatro com e para os bebês, com o projeto "A creche e o teatro" em Bologna, na Itália, além de oficinas formativas sobre o teatro com os/as profissionais das creches.
} 
importância de considerar todos os elementos da composição teatral como a cenografia, figurino, maquiagem, iluminação e sonoplastia, entre outros que dialogam diretamente com o ator e o espectador.

Durante muito tempo (século XIX e metade do século XX no Ocidente), até em função da sua origem nas representações teatrais da Grécia, a cenografia (do grego skenographie - grafia da cena), esteve muito ligada a um cenário pintado ao fundo do palco (SILVA, 2015).Ou seja, esteve "atrelada à ideia de composição pictória da bidimensionalidade do espaço, a serviço da ilusão teatral" (SILVA, 2015, p. 99). Contudo, alguns encenadores como Artaud, JerzyGrotowisk, Luca Ronconi e Ariane Mnouchkine, buscaram estabelecer "novas relações com espectador, diferente da relação distante, passiva e estática, imposta pelo edifício de palco italiano" (SILVA, 2015, p. 99), ampliando a ideia de cenografia.

Para Serroni (2013)

[...] o valor da cenografia não está na quantidade de efeitos especiais ou de elementos no palco. [...] O espaço do palco pode ser cenografia, a luz pode ser cenografia, um efeito sonoro pode ser cenografia, a movimentação dos atores no palco pode ser cenografia. Interessa que essas formas tenham conteúdo, significados, que criem espaço dramático (SERRONI, 2013, p. 28).

Pavis (2005) apresenta diversas categorias de espaço teatral, como o dramatúrgico, o cênico, o lúdico gestual, entre outros. Desta forma, "o espaço lúdico gestual é o espaço criado pelo ator, por sua presença e seus deslocamentos, por sua relação com o grupo, sua disposição" no espaço (PAVIS, 2005, p. 132). Neste sentido, a movimentação do Gabriel $^{12}$, interagindo com sua sombra constitui-se em um cenário, um espaço lúdico gestual, conforme observamos no relato a seguir.

Acompanhamos as crianças de uma turma de berçário no período da manhã e a luz do sol atravessa pela janela e bate na parede da sala. Gabriel (18 meses) parece intrigado com a sombra que se produz na parede. Ele se movimenta de um lado para o outro, acompanhando a sombra na parede. Coloca o dedo e depois o retira. Tenta pegar a sombra e depois a empurra para o lado como se quisesse retirá-la de lá. São poucos segundos e Gabriel já se entretém com outra coisa (notas de campo 06/06/2014).

Sequência de imagens 1: a sombra

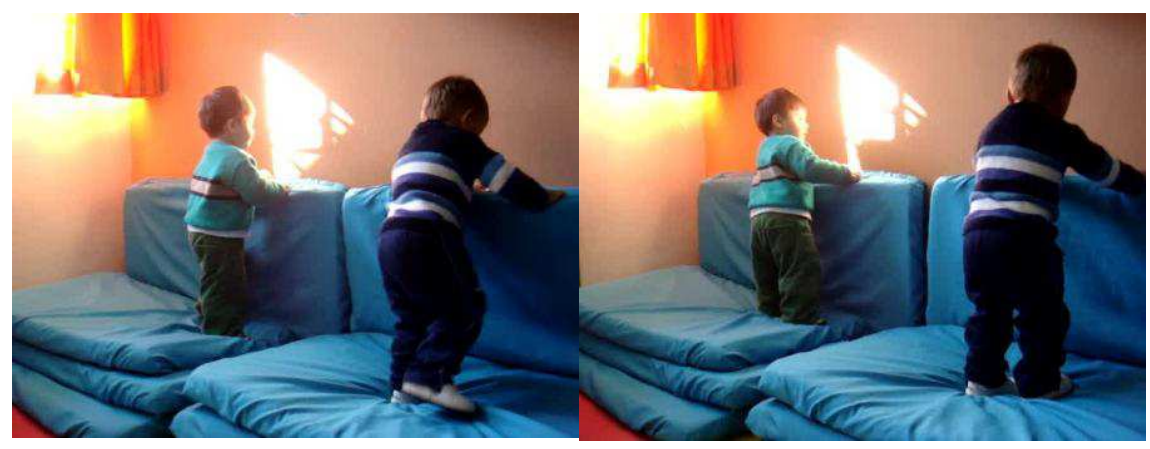

12 Gabriel é um dos sujeitos que participou da pesquisa que culminou na tese mencionada anteriormente. 0 nome das crianças foi mantido conforme Termo de Consentimento Livre e Esclarecido assinado pelo responsável. O estudo foi aprovado no Comitê de Ética em Pesquisa com Seres Humanos, conforme Parecer Consubstanciado n 870.932, de 01/11/2014. 


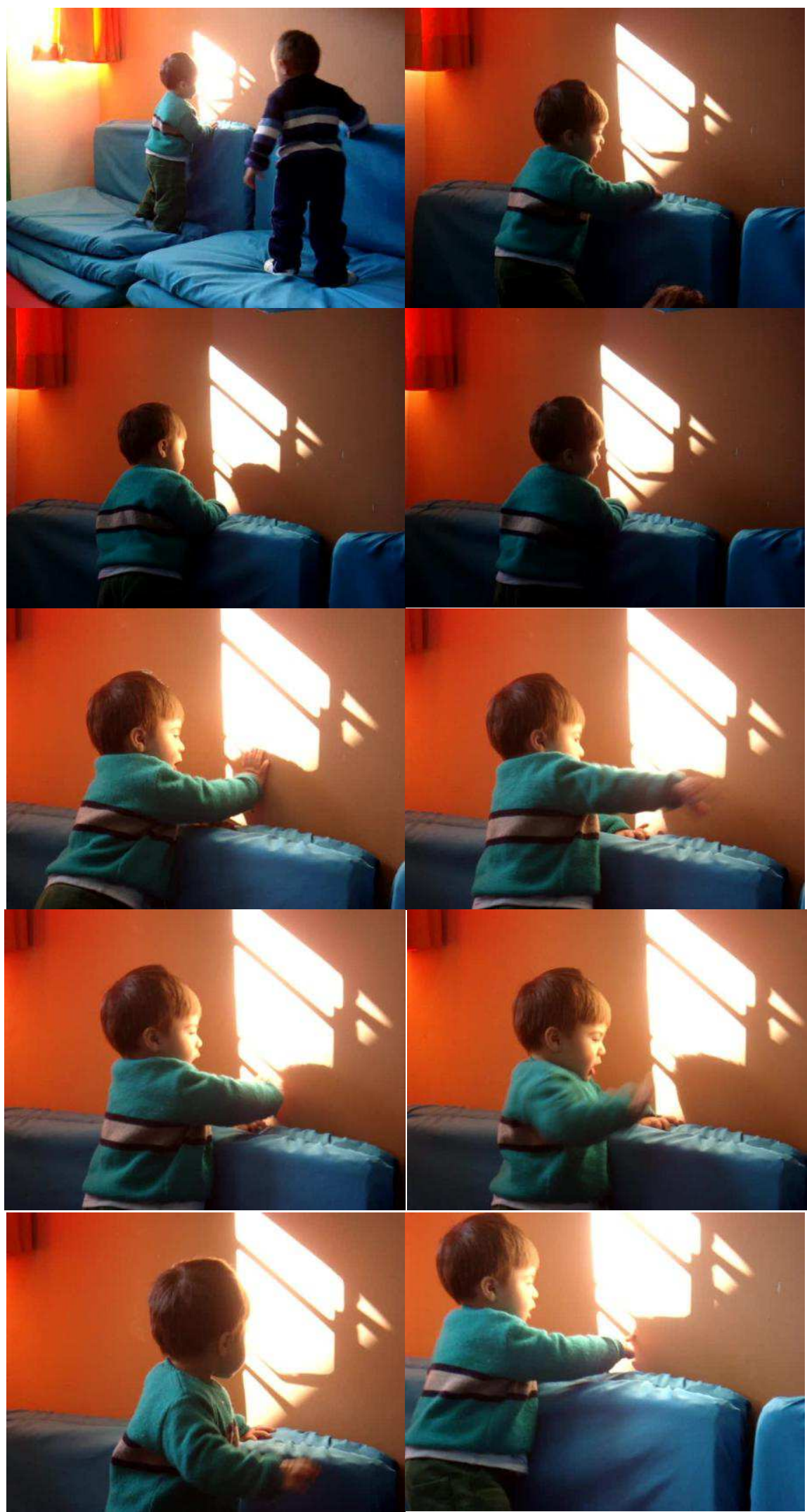

FONTE: acervo da autora (ALESSI, 2014) 
A criança se expressa, portanto, utilizando os recursos de que dispõe para se comunicar, como o choro, o riso ou sorriso, o grito, os gestos, entre outros. A expressão, em uma definição "simples e mais grosseira" (VOLÓCHINOV, 2009, p.115), como diz Volóchinov (2009), se refere a

[...] tudo aquilo que, tendo se formado e determinado de alguma maneira no psiquismo do indivíduo, exterioriza-se objetivamente para outrem com a ajuda de algum código de signos exteriores.

A expressão comporta, portanto, duas facetas: o conteúdo (interior) e sua objetivação exterior para outrem (ou também para si mesmo) (BAKHTIN/VOLÓCHINOV, 2009, p. 115).

A expressão organiza e modela a atividade mental, determinando sua orientação social, tendo em vista os participantes de dada situação. Assim, "sem a linguagem, sem uma enunciação bem definida, verbal ou gestual, não existe expressão; assim como não existe expressão sem uma real situação social com participantes reais". (VOLÓCHINOV, 2013, p. 149).

O autor utiliza o termo expressão avaliativa que consiste em uma avaliação que se transmite de forma material, ou seja, reflete no gesto, no movimento do corpo, destacando assim o caráter corporal que envolve a expressão, que se explica devido a sua natureza social.

Convencionemos chamar toda avaliação encarnada no material de expressão avaliativa. $\mathrm{O}$ material primeiro e antigo desta expressão avaliativa é o próprio corpo humano: o gesto (movimento significativo do corpo) e a $\operatorname{voz}$ (da linguagem articulada). O terror, a alegria, a ira etc. apossam-se primeiro do nosso corpo e da nossa voz: frêmito convulsivo, sorriso, expressão dos olhos etc. - e só depois a expressão avaliativa pode passar, do próprio corpo e através dele, ao material extra-corporal que se limita ao próprio corpo e é quase sua extensão. É absolutamente necessário que este liame com o corpo, efetivo ou possível, seja percebido para que possa ter significado expressivo. Assim, a expressão avaliativa está presente no material linguístico (é o mais próximo do corpo), no material acústico dos sons emitidos pelos corpos físicos (a entonação deixa o corpo e se transmite através da pressão das mãos sobre a testa, a vibração das cordas vocais, a tensão dos lábios e do peito que faz soar a respiração etc.). (VOLÓCHINOV, 2013, p. 237) (Grifos do autor).

Nas imagens de Gabriel brincando com sua sombra, percebemos, através dos seus gestos, o seu processo de descobertas: sobre si mesmo, sobre o outro, sobre o mundo. Machado (2011, p. 58) chama a atenção para os acontecimentos situacionais que ocorrem envolvendo os bebês, onde observamos "coisas interessantes acontecendo: tocáveis, tangíveis, audíveis, palatáveis...cheias de teatralidade, de criação de tempo e de espaços", os chamados "atos performativos e teatralidades dos bebês, como: "gritar, rir, chorar, puxar, cuspir, babar, jogar-se, jogar coisas, dormir, abraçar, fazer careta ou beicinho, apontar, dar tchau, assoprar, bater palmas, beliscar o outro" (MACHADO, 2011, p. 59).

Neste sentido, podemos inferir que os bebês participam de jogos teatrais e constroem espaços de teatralidade desde a tenra idade, como podemos perceber nos gestos da Giovana, que brinca com sua boneca e um cobertor, nas cenas a seguir.

As professoras organizaram um canto da casinha (uma mesa com pratinhos, talheres e copinhos; outra com fogão e panelinha e uma terceira com ferros de passar roupa e tecidos). No tapete, as crianças têm várias bonecas com tecidos e banheirinhas de plástico para as bonecas. Giovana (17 meses) fica durante um longo período cobrindo a boneca. Ela coloca sua boneca dentro da banheira e estica, inúmeras 
vezes, o tecido para cobrir sua boneca. Depois ela volta a arrumar sua boneca dentro da banheira e continua a esticar o tecido. Pega a boneca no colo, mais uma vez, balança as pernas como se a ninasse e dá uma volta com a boneca no colo. A recoloca na banheira e, de novo, estica a coberta. (notas de campo, 23/09/2014).

Sequência de imagens 2: a boneca
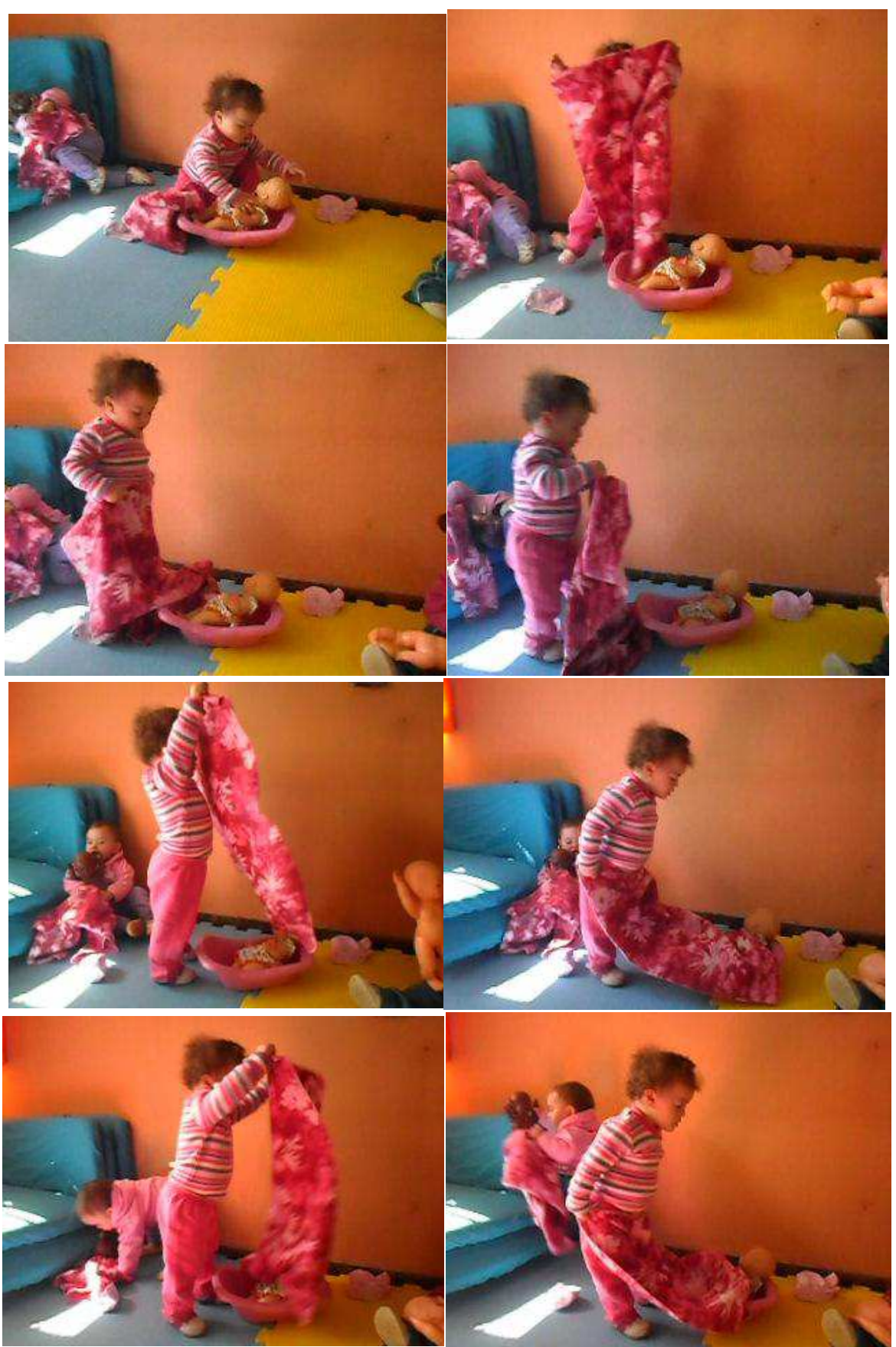


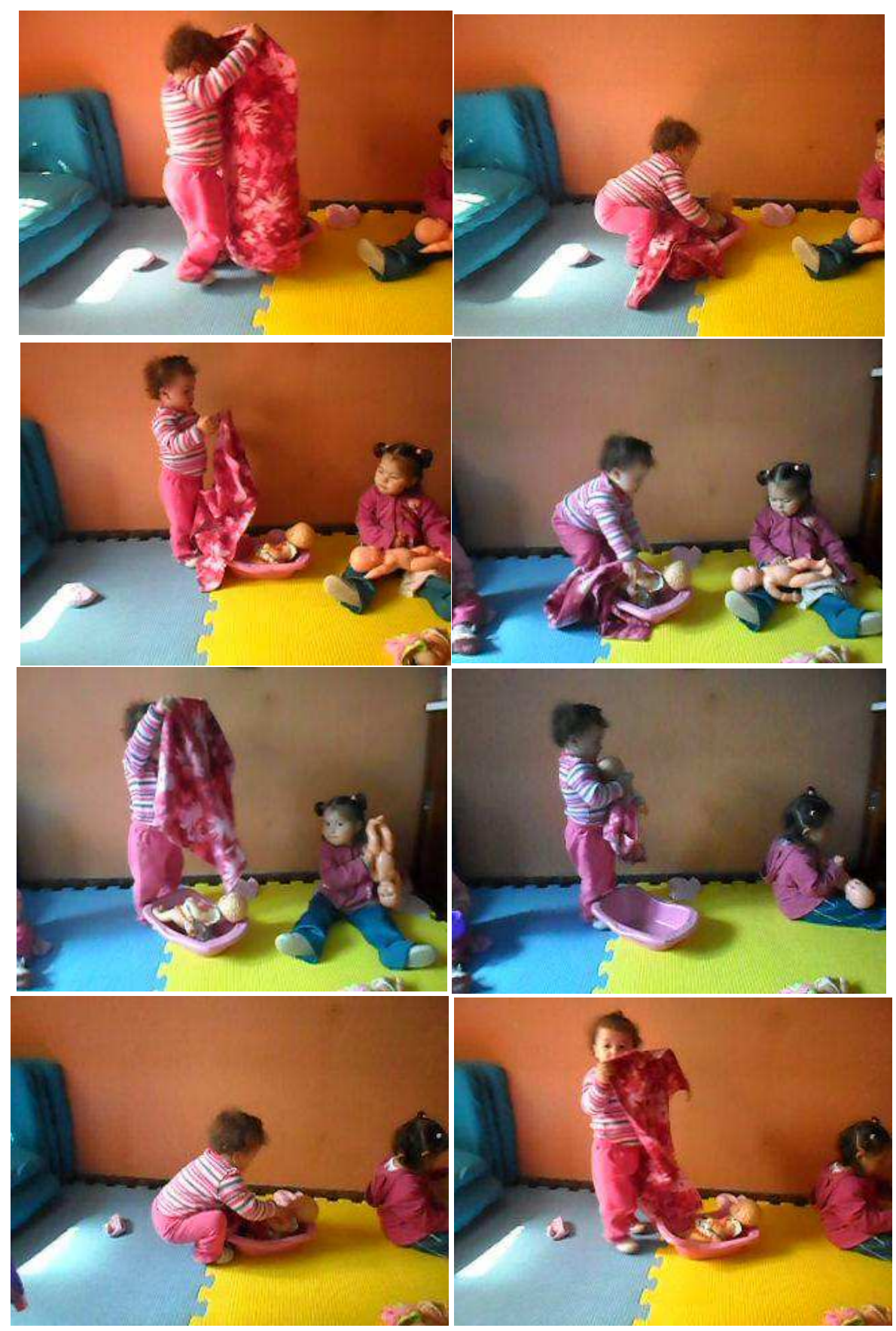

Fonte: acervo da autora(ALESSI, 2014)

Wallon nos lembra que "o gosto pela repetição, o prazer nos atos ou coisas reencontrados são evidentes na criança pequena, deve a isso sua perseverança indispensável para a aprendizagem, ficando longos períodos tomadas por operações puramente lúdicas" (WALLON, 2007, p. 140-141). Giovana está envolvida em uma atividade lúdica de brincar com uma boneca, cobri-la e balançá-la, de forma muito semelhante aos adultos que agem com bebês.

Nestas cenas, duas situações nos chama a atenção: a primeira a semelhança das ações de Giovana com o que comumente vemos em adultos ao embalar e cobrir seus bebês, o que nos leva a crer que, mais do que uma mera imitação dos gestos que observa em seu cotidiano, Giovana esteja reelaborando-o, em 
uma brincadeira de faz de conta. A segunda situação pode ser observada na repetição intensa do bebê em esticar o cobertor na tentativa de cobrir sua boneca. A sensação que temos é de um cuidado e zelo naquilo que está fazendo e que, também, podem refletir situações por ela presenciadas.

Os dois episódios aqui apresentados, revelam que os bebês expressam, através dos gestos, algumas das inúmeras possibilidades da linguagem teatral presente no contexto infantil. Seja através das descobertas realizadas a partir da movimentação do próprio corpo e os efeitos que este produz em contato com a luz, seja através da manipulação de materiais e/ou brinquedos em uma brincadeira de faz de conta. São momentos lúdicos, de brincadeiras e descobertas que permitem às crianças o desenvolvimento das garatujas teatrais (FRABETTI, 2011), ou seja, as primeiras expressões teatrais dos bebês.

Longe da perspectiva de teatro para bebês, que pressupõe a cobrança de ingressos ou a contenção do bebê na poltrona de uma sala de espetáculo, Marina Machado defende que o teatro para bebês

[...] deverá ser fenômeno da vida pulsando, sinônimo de um adulto narrador de coisas do mundo por perto, liberdade de ir e vir; é aprender, mergulhado na experiência, a interpretar o mundo, de modo próprio, significativo e compartilhado. Ele é especialmente fruição e pesquisa de gesto espontâneo, algo que paradoxalmente depende de um ambiente propício, proporcionado por adultos cuidadores e cuidadosos, pessoas ordinárias e comuns - prescinde de produtos culturais, dramaturgos, atores e figurinistas 'especialistas em'. Nesta perspectiva, a criança na tenra infância já se encontra mergulhada em potencialidades estéticas, artísticas e criadoras; ela é ser-nomundo. (MACHADO, 2011, p. 63).

Mais do que um corpo no mundo, como nos diz Boal (2006), no início deste estudo, o bebê é um ser no mundo que se expressa e se comunica através de diferentes linguagens, inclusive a teatral, através de brincadeiras de faz de conta e das inúmeras descobertas que está realizando com o seu corpo e suas potencialidades e capacidades.

É importante ressaltar que não podemos negligenciar a

[...] atividade lúdica de caráter dramático, principalmente, por ser uma das fontes de expressividade humana. É importante refletir como se dá o contato com a linguagem teatral na educação infantil, tendo sempre em mente as relações existentes entre o lúdico e a cultura infantil (CURITIBA, 2011,p. 90).

Portanto, faz-se primordial que os profissionais que atuam com os bebês compreendam as suas linguagens e contribuam para a ampliação das mesmas. Para Barbosa e Fochi (2011), a necessidade de abordar no trabalho formativo com as professoras da educação infantil as experiências teatrais

[...] nasce da percepção de que as crianças constroem suas formas de comunicação e relação com o mundo também dentro da creche, sendo imprescindível disponibilizarem e agirem interlocutivamente - não somente de forma oral, mas também corporal - nesse jogo de comunicação e relação, justificando a necessidade da experiência de formação no teatro" (FOCHI, BARBOSA, 2011, p. 35).

É preciso ter sensibilidade, escuta e olhar atento para perceber as garatujas teatrais dos bebês e permitir que eles brinquem, interajam e ampliem suas possibilidades expressivas, garantindo a qualidade no desenvolvimento integral das crianças que frequentam instituições educativas. 


\section{Referências}

ALESSI, Viviane Maria. As linguagens dos bebês na Educação Infantil: diálogos do Círculo de Bakhtin com Henri Wallon. 142 f. Tese (Doutorado em Educação) - Universidade Federal do Paraná, Curitiba, 2017.

BAKHTIN, Mikhail Mikhailovitch; VOLÓCHINOV, Valentin Nikolaevich. Marxismo e filosofia da linguagem: problemas fundamentais do método sociológico da linguagem. Tradução de: LAHUD, Michel; VIEIRA, Yara Frateschini. São Paulo: Hucitec, 2009.

BARBOSA, Maria Carmen Silveira. FOCHI, Paulo Sergio. O teatro e os bebes: trajetórias possíveis para uma pedagogia com crianças pequenas. Espaços da escola. Editora Unijuí, ano 21, n. 69, jan.jun. 2011, p. 29-38.

BOAL, Augusto. Quando nasce um bebê: o pensamento sensível e o pensamento simbólico no teatro do Oprimido.Sala Preta, São Paulo, n.6, 2006.

CASTRO, Gilberto. Bakhtin e a análise do discurso. In: PAULA, Luciane; STAFUZZA, Grenissa (Orgs.). Da análise do discurso no Brasil à análise do discurso do Brasil: três épocas histórico-analíticas. Uberlândia: EDUFU, 2010. p. 89-118.

CURITIBA. Prefeitura Municipal. Secretaria Municipal da Educação. Caderno Pedagógico: Arte. Curitiba, 2011.

FRABETTI, Roberto. A arte na formação de professores de crianças de todas as idades: o teatro é um conto vivo. Pro-Posições, Campinas, v. 22, n. 2 (65), p. 39-50, maio/ago. 2011.p. 189-195.

GERALDI, João Wanderley. Introdução: o mundo não nos é dado, mas construído. In: VOLÓCHINOV, Valentin Nikolaevich. A construção da enunciação e outros ensaios. São Carlos: Pedro \& João Editores, 2013.

MACHADO, Marina Marcondes. Teatralidade na tenra idade, ou bolacha recheada na cena contemporânea. Lamparina. Revista de Ensino de teatro. Vol. 1, n. 02/2011, EBA/UFMG. p. 56-64

PAVIS, Patrice. Dicionário de Teatro. Tradução de J. Guinsburg e Maria Lúcia Pereira. São Paulo: Perspectiva, 2005.

SERRONI, José Carlos. Cenografia brasileira: notas de um cenógrafo. São Paulo: SENAC, 2013. 
SILVA, Ana Luiza Palhano Campos. A cenografia na sala de aula: apontamento para uma prática pedagógica no ensino fundamental. Revista Moringa - Artes do Espetáculo, João Pessoa, UFPB, v. 6 n. 2, jul/dez 2015, p. 95-108.

VOLÓCHINOV, Valentin Nikolaevich. A construção da enunciação e outros ensaios. Organização, tradução e notas de: GERALDI, João Wanderley. São Carlos: Pedro \& João Editores, 2013.

WALLON, Henri. Do ato ao pensamento: ensaio de psicologia comparada. Petrópolis: Vozes, 2008.

WALLON, Henri. A evolução psicológica da criança. São Paulo: Martins Fontes, 2007. 